\title{
State of microbiocenosis of southern chernozem under the no-till system
}

\author{
$T N$ Melnichuk $^{1,2}, A Y u$ Egovtseva $^{1, *}, S F$ Abdurashytov $^{1}, E R$ Abdurashytova $^{1}, E N$ Turin $^{1}$, \\ $A A$ Gongalo $^{1}, A$ A Zubochenko ${ }^{1}$, and $V S$ Pashtetskiy ${ }^{1}$ \\ ${ }^{1}$ Research Institute of Agriculture of Crimea, 150 Kievskaya str., Simferopol, Republic of Crimea, \\ 295453 \\ ${ }^{2}$ V.I. Vernadsky Crimean Federal University, Prospekt Vernadskogo 4, Simferopol, Republic of \\ Crimea, 295007
}

\begin{abstract}
Agricultural technologies aimed at reducing the tillage can be adopted as safer farming methods to preserve and improve the diversity of soil microbial communities. The area under the promising resource-saving no-till system (direct sowing) is increase in the conditions of the Steppe annually. The use of herbicides in such a farming system causes a negative effect on the soil biocenosis. But the introduction of agronomically useful microorganisms into the rhizosphere are increasing the resistance of plants against stress factors, their yields and product quality, and preserving soil fertility. The objective of this research was to assess the state of microbiocenosis of southern chernozem under the influence of no-till system and a complex of microbial preparations. The influence of direct sowing and microbial preparations on the state of microbocenosis of southern chernozem was established. The number of cellulolytic microorganisms increased under the influence of farming systems in comparison with the virgin soil. The use of microbial preparations contributed to an increase in the number of microorganisms of ecological and trophic groups and the representation of the majority of phyla, which also depended on the system of agriculture. A decrease in the representation of Acidobacteria and Verrucomicrobia and an increase in Firmicutes and Proteobacteria were observed in comparison with virgin soil.
\end{abstract}

\section{Introduction}

Agricultural technologies that aim to reduce tillage can be adopted as safer farming methods to preserve and improve the diversity of soil microbial communities [1]. Microbial communities of soil agroecosystems, as well as the direction of microbiological processes in them, depend on the impact of technological techniques for growing crops. Different farming methods favor dissimilar microbial strategies of vital functions [2]. The use of

\footnotetext{
*Corresponding author: eau82@mail.ru
} 
sustainable farming methods that preserve biological diversity is important for ensuring long-term patterns of soil use in crop production [3].

An increase in the area under the promising resource-saving no-till system (direct sowing (DS)) agriculture occurs annually in the conditions of the Steppe [4-5]. The use of herbicides causes a negative impact on the soil biocenosis in this system of agriculture.

The introduction of agronomically useful microorganisms into the rhizosphere contributes to the activation of processes that are aimed at increasing the resistance of plants against stress factors, their productivity and product quality, and preserving soil fertility [6]. Microorganisms participate in the transformation of mineral and organic compounds, synthesize biologically active substances, can cause changes in the physical and chemical properties of the soil and are biological indicators of its state [7-8].

Questions of studying the influence of microorganisms introduced into the rhizosphere of plants on the state of soil microbiocenosis are relevant in no-till conditions.

The objective of this research was to assess the state of microbiocenosis of southern chernozem under the influence of no-till system and a complex of microbial preparations.

\section{Materials and methods}

\subsection{Research conditions}

The research was carried out in a five-field crop rotation in the stationary experiment on the study of no-till technology in comparison with the traditional farming system (TS) in the central steppe zone of Crimea in 2017-2019. The soils are represented by southern chernozem, which weakly humus, developed on Quaternary yellow-brown loesslike light clays, by WRB classification Haplic Chernozem, Loamic, Aric. The experimental plot was divided into two parts: control $(\mathrm{C})$ - without inoculation and pre-sowing treatment of seeds with a complex of microbial preparations (CMP) developed for each culture. CMP differed in their strains, but all contained nitrogen-fixing, phosphate-mobilizing and phytopathogenprotecting microorganisms from the Crimean collection of microorganisms (http://www.ckp-rf.ru). Soil sampling for analysis was carried out in the first decade of October before sowing winter crops from the $0-10 \mathrm{~cm}$ layer. Quantity of soil microorganisms of the main ecological-trophic groups (ammonifying and amylolytic bacteria, nitrogen fixing bacteria, micromycetes, cellulosolytics, actinomycetes, oligotrophs and pedotrophs) in winter wheat rhizosphere was determined by generally accepted methods $[9,10]$. It is shown in colony-forming units (CFU) per g of dry soil.

\subsection{DNA extraction and sequencing}

Taxonomic analysis of the soil microbiome was performed in 2018 (the second year of notill application) using high-throughput sequencing. The research was performed with equipment of the Core Centrum 'Genomic Technologies, Proteomics and Cell Biology' in ARRIAM. For this, total DNA was isolated from soil samples using the PowerSoil DNA Isolation Kit (Qiagen, Germany), on a Vortex Genee-2 instrument (Mo-bio, USA) according to the manufacturer's protocol. DNA purification was carried out electrophoretically followed by extraction from agarose gel [11]. Purified DNA preparations were used to create libraries of the 16S rRNA gene by PCR using universal primers for the V4 variable region: F515 / R806 (GTGCCAGCMGCCGCGGTAA / GGACTACVSGGGTATCTAAT) [12], as well as by connecting adapters and unique barcodes of the Illumina. Further library preparation and sequencing was carried out in accordance with the manufacturer's recommendations on the «Illumina MiSeq» platform 
(Illumina, USA) using the MiSeq ${ }^{\circledR}$ ReagentKit v3 reagent kit (600 cycle) with two-sided reading $(2 * 300 \mathrm{bp})$.

The initial processing of the obtained data, namely, demultiplexing of samples and removal of adapters, was carried out by Illumina software (Illumina Inc., USA). The software packages dada2 [13], phyloseq [14], and DECIPHER [15] were used for subsequent denoising, combining sequences, removing chimeric readings, restoring the original phylotypes (ASV, Amplicon sequence variant), and further taxonomic classification of the resulting ASVs, which were carried out in software environment R. Means of the QIIME software package [16] were used to represent taxonomic analysis data. The taxonomic and statistical analysis of the results was obtained using the PAST3 software packages [17].

\section{Results and discussion}

Microbiological analysis of southern chernozem showed quantitative differences in the composition of microorganisms of ecological-trophic groups in agrocenoses compared to virgin soil. The differences depended on the weather conditions of the research year (fig. 1, table 1). A higher number of microorganisms was detected after treatment by the CMP. The decomposition of organic nitrogen-containing compounds is mainly carried out by ammonifying bacteria, which can use extracellular enzymes to convert some of the protein nitrogen into a form accessible to plants [18]. The amount of precipitation was 2.7 times higher than the annual average in the September 2018. The increase in the number of ammonifying, amylolytic and pedotrophic microorganisms observed under direct sowing compared with conventional system in the conditions this year. Reverse trends were observed in 2019, with quantitative indicators for DS at the level of virgin soil.

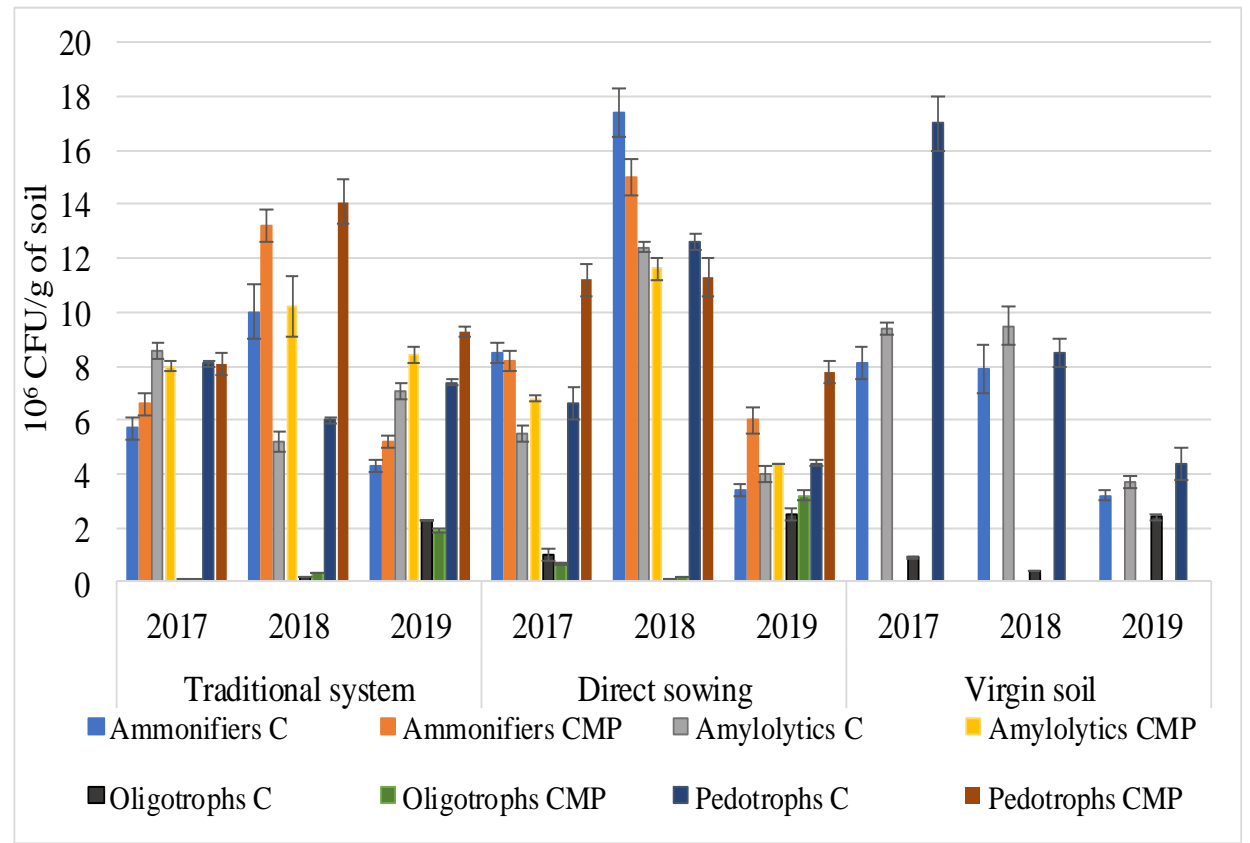

Fig. 1. Influence of farming systems and complex of microbial preparations on the quantity of ecological-trophic groups microorganisms of southern chernozem. Notes: $\mathrm{C}$ - control without treatment; CMP - complex microbial preparations. 
Oligonitrophilic microorganisms needs the minimum quantity of the organic nitrogencontaining substances [19]. The maximum number of them is recorded in the version of the TS with the CMP for two years $(2018,2019)$. Cellulolytics and actinomycetes decompose complex polymer compounds and play an important role in the substance turnover [20]. The annual increase in the number of cellulolytics was observed in the southern chernozem as a result of the action of microbial preparations when using the traditional farming system by 1.3-2.6 times. The content of micromycetes increased under the influence of farming systems in 2019 compared to virgin soil. The use of microbial preparations contributed to an increase in their number in both farming systems.

Table 1. Influence of farming systems and complex of microbial preparations on the number of microorganisms of southern chernozem, million CFU / g of soil.

\begin{tabular}{|c|c|c|c|c|c|c|c|c|}
\hline \multirow{3}{*}{ Year } & \multirow{2}{*}{\multicolumn{2}{|c|}{$\begin{array}{l}\text { Nitrogen-fixing } \\
\text { microorganisms }\end{array}$}} & \multirow{2}{*}{\multicolumn{2}{|c|}{ Actinobacteria }} & \multirow{2}{*}{\multicolumn{2}{|c|}{ Micromycetes * }} & \multicolumn{2}{|c|}{ Cellulosolytic * } \\
\hline & & & & & & & & \\
\hline & $\mathrm{C}$ & CMP & $\mathrm{C}$ & CMP & $\mathrm{C}$ & CMP & $\mathrm{C}$ & CMP \\
\hline \multicolumn{9}{|c|}{ Traditional system } \\
\hline 2017 & $9,7 \pm 0,3$ & $7,0 \pm 0,3$ & $0,4 \pm 0,1$ & $0,4 \pm 0,0$ & $44,5 \pm 4,1$ & $58,1 \pm 5,0$ & $3,0 \pm 0,4$ & $7,9 \pm 0,8$ \\
\hline 2018 & $5,5 \pm 0,4$ & $10,6 \pm 05$ & $0,4 \pm 0,1$ & $0,2 \pm 0,0$ & $29,9 \pm 2,9$ & $23,7 \pm 2,2$ & $15,6 \pm 1,8$ & $24,1 \pm 0,7$ \\
\hline 2019 & $2,9 \pm 0,2$ & $6,0 \pm 0,4$ & $0,4 \pm 0,0$ & $0,6 \pm 0,0$ & $19,2 \pm 2,0$ & $37,6 \pm 2,3$ & $31,1 \pm 1,9$ & $40,7 \pm 1,4$ \\
\hline \multicolumn{9}{|c|}{ Direct sowing } \\
\hline 2017 & $7,2 \pm 0,2$ & $8,0 \pm 0,2$ & $0,4 \pm 0,1$ & $0,2 \pm 0,0$ & $38,4 \pm 2,4$ & $42,6 \pm 3,9$ & $8,5 \pm 0,4$ & $11,1 \pm 0,7$ \\
\hline 2018 & $12,3 \pm 0,1$ & $8,0 \pm 0,6$ & $0,7 \pm 0,2$ & $0,7 \pm 0,1$ & $15,8 \pm 0,8$ & $27,9 \pm 4,6$ & $12,9 \pm 1,1$ & $14,2 \pm 0,8$ \\
\hline 2019 & $1,3 \pm 0,1$ & $2,5 \pm 0,1$ & $0,5 \pm 0,1$ & $0,4 \pm 0,1$ & $15,3 \pm 1,0$ & $19,7 \pm 4,2$ & $33,4 \pm 2,4$ & $32,5 \pm 1,8$ \\
\hline \multicolumn{9}{|c|}{ Virgin soil } \\
\hline 2017 & \multicolumn{2}{|c|}{$8,9 \pm 0,2$} & \multicolumn{2}{|c|}{$0,5 \pm 0,1$} & \multicolumn{2}{|c|}{$66,6 \pm 3,2$} & \multicolumn{2}{|c|}{$8,9 \pm 1,1$} \\
\hline 2018 & \multicolumn{2}{|c|}{$10,7 \pm 0,6$} & \multicolumn{2}{|c|}{$0,6 \pm 0,1$} & \multicolumn{2}{|c|}{$30,2 \pm 2,9$} & \multicolumn{2}{|c|}{$11,3 \pm 1,9$} \\
\hline 2019 & \multicolumn{2}{|c|}{$3,8 \pm 0,7$} & \multicolumn{2}{|c|}{$0,5 \pm 0,1$} & \multicolumn{2}{|c|}{$11,6 \pm 1,3$} & \multicolumn{2}{|c|}{$20,9 \pm 1,3$} \\
\hline
\end{tabular}

Today it is possible to use the relative content of taxa as biological indicators of soil condition [8]. Metagenomic analysis of the taxonomic structure of the southern chernozem allowed us to identify representatives of 12 prokaryotic phyla. There were eleven of them in the domain Bacteria, and one among the Archaea (fig. 2).

The proportion of Proteobacteria and Actinobacteria was an order of magnitude higher than the other five dominant phyla (above 1\%). A decrease in the representation of Acidobacteria and Verrucomicrobia and an increase in the Firmicutes and Proteobacteria was observed in comparison with virgin soil. Direct sowing conditions contributed to an increase in the representation of Bacteroidetes and Thaumarchaeota.

The ability to react to the content of macro- and microelements of the soil and its acidity is known among the ecologically significant functions of the Acidobacteria [21]. The Acidobacteria are widely distributed in soils, having genomic, physiological and metabolic flexibility [22]. The smallest share was observed in DS, which is 1.6 times less than virgin 
land. Inoculation contributed to its increase only under the traditional system of agriculture (1.2 times).

Representatives of phylum Verrucomicrobia can act as an indicator of soil fertility [23]. Their share decreased by 3.9 times under the influence of the TS, while the use of CMP increased it by 1.4 times in the conditions of stationary experiment. The decrease was 2.8 times for DS.

The Firmicutes participate in the decomposition of complex organic substances and play an important role in maintaining the stability of the rhizosphere microbiome [24-25]. The representation of Firmicutes increased under the influence of farming systems by 2.9 times compared to the virgin soil in the conditions of chernozem in our field research. The influence of microbial preparations depended on the system of agriculture: in the traditional system, the share decreased by 1.8 times, and the increase by 1.2 times when using direct sowing.

Microorganisms from the phylum Actinobacteria plays an important role in soil development and nitrogen cycling in both desert and cultivated agroecosystems [26]. The Actinobacteria in the conditions of using of the TS had 1.3 times more representation than in virgin lands.

Representatives of Proteobacteria phylum play a key role in the geochemical cycle of carbon, nitrogen and sulfur. An increase of 1.3 times in their representation in both systems was noted in comparison with the virgin soil. The same increase in the share was found when applying the CMP in DS, while under the traditional system, no changes were found.

Archaea, primarily from the phylum Crenarchaeota, are widely distributed in the soil; their representation is higher in soils with lower C:N ratios [21]. The Thaumarchaeota are able to oxidize ammonia low concentrations in the environment where they are located, which is the difference between ammonia-oxidizing bacteria, and therefore, probably dominate in oligotrophic conditions. [27-28]. The proportion of phylum Thaumarchaeota was 1.3 times greater under direct sowing, while under the traditional farming system it was 1.4 times less in comparison with virgin soil. The use of the CMP did not significantly affect the number of archaea. 


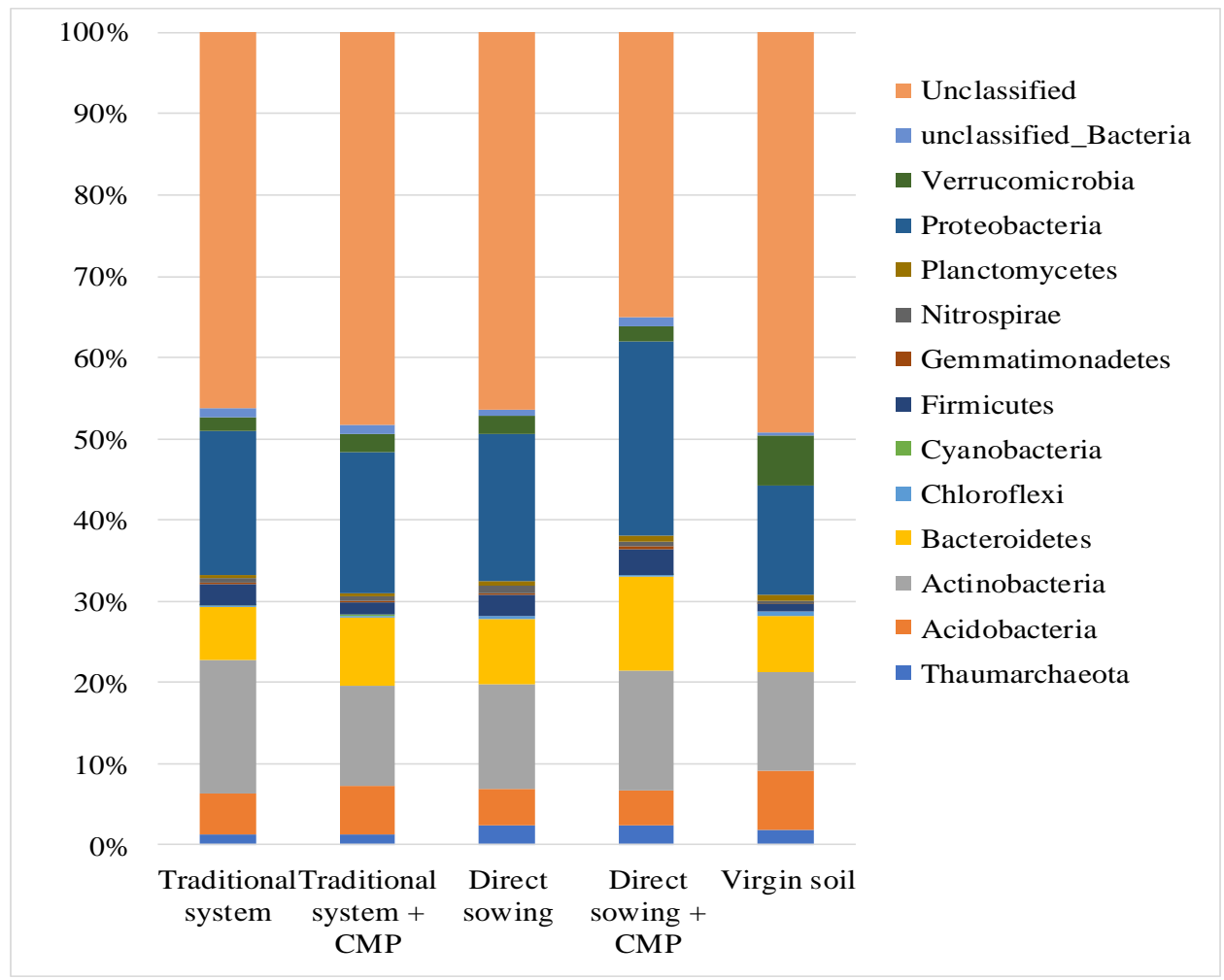

Fig. 2. Taxonomic structure of the southern chernozem of prokaryotic biome under the influence of the CMP and farming systems according to the analysis of the 16s rRNA metagenome.

Bacteria from the phylum Planctomycetes participate in the decomposition of plant residues and are sensitive to soil $\mathrm{pH}[29,30]$. Minor fractions of Chloroflexi and Planctomycetes were found, which decreased in agrocenoses by 4.6 and 1.7 times under the TS and 1.5 and 1.1 times under DS, respectively, in comparison with virgin land. In contrast, increases in the representation of Cyanobacteria from $0 \%$ in virgin lands to $0.18 \%$ were observed in TS, Gemmatimonadetes and Nitrospirae by 1.9 times in TS and 1.6 and 2.8 times in DS, respectively. Representatives of Gemmatimonadetes predominate in arable soils compared with fallow [31] and no-till [32]. The same tendencies were revealed in the southern chernozem. It was found that the share of this phylum in the traditional system and direct sowing was higher in 1.9 and 1.6 times than in the virgin soil.

A large percentage of the unclassified prokaryotes was established. It was the maximum and amounted to $49.2 \%$ in virgin lands, with farming systems $-46.3 \%$. The use of microbial preparations reduced the share of them in the variant without tillage by 1.3 times.

\section{Conclusion}

Thus, the influence of direct sowing and microbial preparations on the state of microbiocenosis of southern chernozem was established. Quantity of cellulolytic microorganisms increased under the effect of farming systems in comparison with the virgin soil. The use of microbial preparations contributed to an increase in the number of microorganisms of ecological-trophic groups and the representation of the majority of phyla, which also depended on the agriculture system. A decrease of the representation of 
Acidobacteria and Verrucomicrobia and an increase of the Firmicutes and Proteobacteria were detected in comparison with virgin soil.

The work was carried out within the Framework of the State Assignment of Fundamental Research No. 0834-2019-0004 and with the support of the Core Centrum 'Genomic Technologies, Proteomics and Cell Biology' (ARRIAM).

\section{References}

1. Ceja-Navarro J A, Rivera-Orduna F N, Patino-Zuniga L, Vila-Sanjurjo A, Crossa J, Govaerts B, Dendooven L 2010 Applied And Environmental Microbiology 76(11) 3685-3691

2. Schmidt R, Gravuer K, Bossange A, Mitchell J, Scow K 2018 PLoS One 13(2) e0192953. doi: 10.1371/journal.pone.0192953

3. Draghi W O, Degrossi J, Bialer M et al 2018 PLoS ONE 13(7) e0200651

4. Kulincev V V, Dridiger V K 2014 Achievement of science and technology of agribusiness 4 16-18

5. Turin E N 2020 Taurida Herald of Agricultural Science 2(22) 150-168 Doi 10.33952/2542-0720-2020-2-22-150-168

6. Jacoby R, Peukert M, Succurro A, Koprivova A and Kopriva S 2017 Front. Plant Sci. 8 doi: $10.3389 /$ fpls.2017.01617

7. Zhuikova T V, Gordeeva V A, Bezel' V S 2017 Biology Bulletin 44(10) 1228-1236 doi.org/10.1134/S1062359017100193

8. Hermans S M, Buckley H L, Case B S, Curran-Cournane F, Taylor M, Lear G 2017 Applied and Environmental Microbiology 83(1) e02826-16 doi: 10.1128/AEM.0282616.

9. Volkogon V V 2010 Experimental soil microbiology (Kiev: Agrarna nauka)

10. Tepper E Z, Shilnikova V K, Pereverzeva G I 2005 Workshop on Microbiology (Moscow: Drofa)

11. Andronov E E, Pinaev A G and Pershina E V 2011 Isolation of DNA from soil samples (St. Petersburg: PC "Association Venta")

12. Bates S T, Berg-Lyons J G, Caporaso W A et al 2010 ISME J. 5 908-917

13. Callahan B J, McMurdie P J, Rosen M J, Han A W, Johnson A J A, Holmes S P 2016 Nature Methods 13 581-583 doi:10.1038/nmeth.3869

14. McMurdie and Holmes 2013 PLoS ONE 8(4) e61217

15. Wright E S 2016 The R Journal 8(1) 352-359

16. Caporaso J G, Kuczynski J, Stombaugh J et al. 2010 Nature methods 7(5) 335-336 doi:10.1038/nmeth.f.303

17. Hammer $\varnothing$, Harper D A T and Ryan P D 2001 Palaeontologia Electronica 4(1) 1-9

18. Khasanova R F, Suyundukov Ya T, Semenova I N 2014 Pochvovedenie 8 982-982

19. Zinchenko M K, Stoyanova L G 2015 Vladimir farmer 2 (72)

20. Větrovský T, Steffen K T, Baldrian P 2014 PloS one 9(2) p.e89108

21. Kielak A M, Barreto C C, Kowalchuk G A, A van Veen J, Kuramae E E 2016 Front Microbiol. 7 doi: 10.3389/fmicb.2016.00744

22. Eichorst S A, Trojan D, Roux S, Herbold C, Rattei T, Woebken D 2018 Environmental Microbiology 20(3) 1041-1063 doi:10.1111/1462-2920.14043 
23. Navarrete A A, Soares T, Rossetto R, Antonie van Veen J, Tsai S M, Kuramae E E 2015 Antonie van Leeuwenhoek 108 741-752 doi 10.1007/s10482-015-0530-3

24. Wei Z, Hu X, Li X, Zhang Y, Jiang L, Li J 2017 PLoS ONE 12(4) e0174411 doi.org/10.1371/journal. pone.0174411

25. Hartmann M, Frey B, Mayer J, Mäder P, Widmer F 2015 ISME J 9(5) 1177-1194

26. Zhang B, Wu X, Tai X, Sun L, Wu M, Zhang W, Chen X, Zhang G, Chen T, Liu G, Dyson P 2019 Front. Microbiol. doi.org/10.3389/fmicb.2019.02209

27. Pester M, Schleper C, Wagner M 2011 Current Opinion in Microbiology 14(3) 300306 doi:10.1016/j.mib.2011.04.007

28. Könneke M, Schubert D M, Brown P C, Hügler M, Standfest S, Schwander T, Schada von Borzyskowski L, Erb T J, Stahl D A, Berg I A 2014 Proceedings of the National Academy of Sciences of the United States of America. 111(22) 8239-8244 doi:10.1073/pnas.1402028111

29. Ivanova A A, Philippov D A, Kulichevskaya I S, Dedysh S N 2018 Antonie van Leeuwenhoek 111(6) 811-823

30. Constancias F, Saby N P A, Terrat S, Dequiedt S, Horrigue W, Nowak V, Guillemin JP, Biju-Duval L, Chemidlin N Prevost-Bour, Ranjard L 2015 Microbiology 4(3) 518531

31. Pershina E V, Kutovaya O V, Kogut B M, Andronov E E 2017 The main achievements and prospects of soil metagenomics (St. Petersburg: Inform-Navigator)

32. Favaz M N 2013 Thesis (University of Tennessee) https://trace.tennessee.edu/utk_gradthes/1652 